\title{
Operações linguísticas e o processo de aquisição da enunciação escrita
}

\author{
Linguistic operations and the acquisition of enunciation \\ written
}

\author{
Suelen Érica Costa da Silva*
}

\begin{abstract}
RESUMO: O eixo central que norteou este artigo foi a análise das operações linguísticas realizadas pelo falante para representar na (sua) escrita o sujeito que enuncia, o interlocutor, a temática, a finalidade da interação, o tempo, bem como o espaço da enunciação. Para tanto, o quadro teórico que norteia a análise dos corpora selecionados - duas produções textuais de aprendizes em fase de aquisição da escrita - está situado, essencialmente, nos trabalhos de Abaurre (1991) Abaurre e MayrinkSabison (2003) sobre aquisição da linguagem escrita, na Teoria da Enunciação de Benveniste (1995), na proposta de heterogeneidade da escrita de Corrêa (2004), na perspectiva sociointeracionista de Bronckart (1999), na concepção de aprendizagem da escrita de Oliveira (2005) e na concepção de letramento proposta por Soares (2005). Foi utilizado o procedimento metodológico intitulado paradigma indiciário de investigação proposto por Ginzburg (1990) para realizar a análise dos dados linguísticos dos textos produzidos por falantes, pertencentes a classes sociais distintas. Tais dados foram coletados no ano de 1987, durante uma pesquisa a respeito do processo de aquisição da escrita, realizada na Faculdade de Letras e na Faculdade de Educação da Universidade Federal de Minas Gerais - UFMG. O que alguns professores consideram como "erros", "inadequações" são, na verdade, operações linguísticas realizadas pelo falante para construir o conhecimento e o uso da tecnologia da escrita como discurso, como enunciação escrita.
\end{abstract}

PALAVRAS-CHAVE: Aquisição da escrita. Operações linguísticas. Enunciação escrita. Subjetividade.

ABSTRACT: The central axis that has guided this article was the analysis of the linguistic operations realized by the speaker to represent in (their) writing the subject who enunciates, the interlocutor, the theme, the purpose of the interaction, the time and the space of enunciation. Therefore, the theoretical framework that guides the analysis of the selected corpora (two textual productions of learners in writing acquisition phase) is situated mainly in the work of Abaurre (2003), Benveniste (1995),

*Doutoranda em Linguística e Língua Portuguesa pelo Programa de Pós-Graduação em Letras da Pontifícia Universidade Católica de Minas Gerais (PUC-MG). Bolsista da Coordenação de Aperfeiçoamento de Pessoal de Ensino Superior (CAPES). Professora do quadro efetivo do Centro Federal de Educação Tecnológica de Minas Gerais (CEFET-MG). E-mail: suelenerica@gmail.com.

Entretextos, Londrina, v. 15, n. 2, p. 193-215, jul./dez. 2015. 
Bronckart (1999), Corrêa (2004), Hermont (2010), Oliveira (2005) and Smith (2005). A methodological procedure called "research paradigm indiciary" is used to perform the analysis of the linguistic data of the texts produced by speakers belonging to different social classes. These data were collected in 1987 during a survey about writing acquisition process, held at the Faculty of Arts and the Faculty of Education from the Federal University of Minas Gerais - UFMG. What some teachers consider "mistakes," "inadequacies" are actually linguistic operations realizes by the speaker to build the knowledge and the use of the resource of written language as speech, as written enunciation.

KEYWORDS: Acquisition of writing. Linguistic operations. Enunciation writing. Subjectivity.

\section{Considerações iniciais}

A trajetória desta interlocução escrita está circunscrita no chamado processo de aquisição da escrita e, para iniciar uma breve reflexão a respeito de tal temática, o leitor está convidado a observar o texto a seguir, produzido por um falante da língua portuguesa - estudante da $1^{\text {a }}$ série $^{1}$ - ao iniciar o seu processo de aquisição da escrita:

Quadro 1 - Texto 1: falante da classe popular

A xuva
derepente a xuva foi caindo e
O sou feio surjindo
Eu mexamo Lalau
O gatinho Lalau Estava corendo a tra da borboleta
e a borboleta entro dentro da casa e tinha um quadro
parecido com a borboleta e o gatinho emtro na casa e o gatinho
viu o quadro e o gatinho pulou no quadro e o quadro e o quadro
caiu.

Fonte: Dados da pesquisa²

O texto produzido pelo falante apresenta algumas marcas linguísticas que evidenciam, nos planos gráfico e textual, um funcionamento bem distinto

${ }^{1}$ Com a mudança do Ensino Fundamental para 9 anos, o termo 1 ạ série passou a ser denominado como 20 ano do Ensino Fundamental.

2 Dados coletados pelo Professor Dr. Marco Antônio de Oliveira e cedidos para realização da pesquisa de Doutorado cujo título provisório é o exposto neste artigo.

Entretextos, Londrina, v. 15, n. 2, p. 193-215, jul./dez. 2015. 
daquele produzido na e para a escola. São observados os seguintes aspectos: (i) violação das formas dicionarizadas; (ii) distribuição de espaços em branco entre as palavras bem como a separação não convencional; (iii) emprego de letras maiúsculas no meio de frase e de minúsculas no início; (iv) problema de discriminação auditiva; e (v) a ausência de vírgulas e de ponto final.

Para alguns professores, especificamente grande parte dos alfabetizadores, as marcas linguísticas supracitadas, quando comparadas à chamada escrita padrão, evidenciam "inadequações", "erros ortográficos", "distorções", "escrita aleatória", "interferência negativa da fala na escrita, "dificuldade de aprendizagem". Essas considerações depreciativas e sem consistência empírica e científica, construídas nos corredores das escolas, nas reuniões pedagógicas e nas salas de professores contribuem para disseminar o discurso do "erro", a ideia de que o aprendiz que "erra" é aquele que apresenta problemas de aprendizagem, o que "não sabe escrever direito", pois não escreve de acordo com as normas ortográficas.

Essa forma de entender e explicar como ocorre o processo de aquisição da escrita é errôneo porque considera que escrever é utilizar um conjunto de normas e regras, em especial, convenções ortográficas. Tal concepção de escrita como produto desconsidera que além de tentar compreender como funciona a ortografia padrão, o falante irá utilizar a escrita como um exercício da faculdade da linguagem e, assim, construir na (sua) escrita o sujeito que enuncia, o interlocutor, a finalidade da interação, a temática, o lugar e o tempo da produção, a fim de provocar algum efeito de sentido no seu interlocutor, como posto por Antunes (2003).

Antes de ingressar na instituição de educação formal, o falante aprendiz da escrita - já domina a fala, ou seja, é considerado falante nativo do português e com grande domínio da língua oral. Portanto, possui o Conhecimento Linguístico Internalizado - CLI - de natureza oral, e faz uso do mesmo para registrar o código escrito do português. O CLI, segundo Oliveira (2005), diz respeito ao saber linguístico de todos os falantes - inclusive os 
analfabetos - o qual é construído na convivência cotidiana com a família e a comunidade, de forma natural e espontânea, sem a necessidade de aula ou mesmo de exercícios.

Esse conhecimento, segundo o autor, nos capacita a falar e a entender a nossa língua e abrange o vocabulário, as regras gramaticais básicas, as regras de produção de textos, e as regras de comportamento linguístico social (o que se deve dizer em cada situação de comunicação). Desse modo, esse falante, ser social, sujeito da linguagem, antes mesmo de adquirir a tecnologia da escrita, compreende que os textos que ele (enunciador) e o outro (interlocutor) produzem - sejam textos orais, sejam textos escritos - têm uma função social. Em outros termos, percebe que a escrita (como também a fala) “... não existe para nada, para não dizer nada, para não ser ato de linguagem." (ANTUNES, 2003, p. 48).

Logo, o que o falante (e também aprendiz) faz, naturalmente, quando interage com os outros é, segundo Antunes (2003), "construir peças inteiras", textos com unidade, com começo, meio e fim para expressar sentidos e intenções. Em outras palavras, o falante constrói unidades de sentido e de intenções que apresentam (i) um sujeito que enuncia, (ii) um interlocutor, (iii) uma temática, (iv) uma finalidade, (v) um tempo e espaço determinados. Dessa forma, cabe a seguinte indagação: Que operações linguísticas são realizadas pelo falante para representar na (sua) escrita cenas enunciativas ${ }^{3}$ ?

Acreditamos que o texto escrito produzido pelo escrevente - falante da língua e aprendiz da escrita - apresenta operações linguísticas que instauram um sujeito da linguagem, um "eu", que selecionou alguma coisa a ser proferida para outrem, um "tu", com quem pretendeu interagir, a respeito de uma temática, a fim de alcançar um dado objetivo, num dado espaço e tempo de interlocução.

\footnotetext{
${ }^{3}$ Pergunta da pesquisa de doutoramento. Entendemos por cenas enunciativas a construção do enunciador, do enunciatário, da temática, da finalidade da interação e do tempo/espaço da enunciação.
}

Entretextos, Londrina, v. 15, n. 2, p. 193-215, jul./dez. 2015. 
Esse sujeito que enuncia faz uso do seu CLI de natureza oral, levanta hipóteses a respeito do que é escrever e, assim, produz a sua escrita, uma forma particular de enunciação que, na maioria dos casos, é considerada pela escola e pelo professor alfabetizador como "incorreta" por apresentar ora fatos linguísticos atrelados à oralidade, ora fatos linguísticos atrelados à escrita, para estabelecer um processo de interlocução por meio do texto escrito.

Defendemos que os chamados "erros" produzidos pelos aprendizes são operações linguísticas ${ }^{4}$ que marcam a trajetória do aprendiz em sua inserção na escrita convencional. Tais operações, além de apontar para um entrelaçamento entre a oralidade e a escrita, compreendidas neste trabalho como um continuum (MARCUSCHI, 2001), como práticas sociais, evidenciam um modo de enunciação escrito, o trabalho do sujeito aprendiz com a linguagem.

Assim, pretendemos apresentar algumas considerações - mesmo que iniciais e breves - na tentativa de explicar detalhadamente como as operações linguísticas realizadas pelo falante podem ser consideradas como indícios/marcas que revelam na (sua) escrita inicial um tipo particular de enunciação escrita. Para tanto, o quadro teórico que norteia a análise dos corpora selecionados - duas produções textuais de aprendizes em fase de aquisição da escrita - está situado, essencialmente, nos trabalhos de Abaurre (1991) Abaurre e Mayrink-Sabison (2003) sobre aquisição da linguagem escrita, na Teoria da Enunciação de Benveniste (1995), na proposta de heterogeneidade da escrita de Corrêa (2004), na perspectiva sociointeracionista de Bronckart (1999), na concepção de aprendizagem da escrita de Oliveira (2005) e na concepção de letramento proposta por Soares (2005).

A presente interlocução está organizada da seguinte forma: inicialmente apresentaremos: (i) a concepção sociointeracionista de língua, de linguagem, de texto, (ii) a concepção de heterogeneidade da escrita e (iii) as concepções de aprendizagem e de letramento que norteiam a investigação dos fatos

\footnotetext{
${ }^{4}$ Operações fonológicas, morfo-fológicas, morfossintáticas, textuais, semânticas, pragmáticas e lexicais, necessárias para produção do espaço enunciativo denominado texto.
} 
linguísticos. Em seguida, realizaremos a exposição dos corpora, o procedimento de categorização dos dados e a metodologia empregada para realização da pesquisa. Após, faremos a descrição e análise das operações linguísticas realizadas pelos falantes ao produzir textos escritos, a fim de demonstrar o que apontam os dados. Por fim, as considerações finais da investigação.

\section{Pressupostos teóricos que fundamentam a análise dos fatos da linguagem}

Todo fazer científico na área dos estudos da linguagem ou mesmo toda atividade pedagógica de ensino da Língua Portuguesa assume, de forma explícita ou apenas intuitiva, uma dada concepção de língua, linguagem, escrita e texto. Desse modo, nesta investigação, língua é compreendida numa perspectiva sociointeracionista como a soma de usos concretos, realizados por interlocutores que, historicamente situados, utilizam-na para interagir, num determinado espaço, num determinado tempo, com vistas a atingir um determinado propósito comunicativo. Língua-em-função, com uma função: para que um "eu" possa interagir com um "tu" socialmente. Língua é, portanto, uma atividade social, a possibilidade da enunciação como afirma Benveniste (1995).

Esta adesão permite compreender linguagem como a possibilidade que membros de uma dada comunidade possuem para interagir socialmente, atuarem mutuamente com um ou mais interlocutores por meio de textos - orais e escritos - em diferentes contextos, tendo em vista diferentes propósitos comunicativos. Dessa forma, será adotada nesta investigação, a perspectiva sociointeracionista, na qual as ações de linguagem são percebidas em sua relação com a atividade humana em geral, em seus aspectos históricos e sociais, materializadas nos gêneros textuais empíricos.

O sociointeracionista Bronckart (1999) considera que o estudo da linguagem deve ser realizado em suas dimensões discursivas e/ou textuais. Nesse sentido, os textos e/ou discursos são as únicas manifestações que 
permitem aos pesquisadores da linguagem observar, de forma empírica, as ações de linguagem humanas. É em textos e/ou discursos - unidades globais que são manifestadas, materializadas, de forma mais nítida, as relações de interdependência entre produções de linguagem e seu contexto acional e social.

Semelhante a Bronckart (1999), defendemos, neste estudo, que a atividade da linguagem pode ser compreendida como ação, sendo responsável por tal um "eu" que se dirige a um "tu" e vice-e versa - a partir de características específicas de uma dada língua e, por meio delas, materializa uma ação de linguagem - seja ela oral ou escrita - em textos empíricos, por meio de operações linguísticas (ou de linguagem e ou textuais discursivas). Postulamos que diversas operações linguísticas serão necessárias para produção de textos e/ou discursos, estes que são sempre respostas de um "eu" para um "tu" e vice-e-versa.

Nessa perspectiva, fica claro que texto empírico é visto como "produções verbais efetivas, que assumem aspectos muito diversos, principalmente por serem articuladas a situações de comunicação muito diferentes. São essas formas de realizações empíricas diversas que chamamos de textos." (BRONCKART, 1999, p. 6). O pesquisador salienta ainda que essa primeira definição de texto designa toda unidade de produção de linguagem que veicula uma mensagem linguisticamente organizada e que tem a tendência de produzir um efeito de coerência sobre o destinatário.

Dessa forma, texto, enquanto processamento da linguagem e do discurso, é um produto da atividade humana e, portanto, está atrelado às necessidades, aos interesses e às condições de funcionamento das formações sociais no seio das quais é produzido. $E$, além de ser um espaço social, servir aos interesses e funcionamento das formações da sociedade, cada texto exibe características individuais e, por tal, pode ser compreendido como um objeto único, singular, o que leva o pesquisador a discorrer a respeito da noção de textos singulares ou empíricos. 
De acordo com o linguista, o agente verbal dispõe de certo conhecimento de gêneros e dos tipos em uso ${ }^{5}$, constituídos como modelos sociais ou exemplos. No entanto, a situação de comunicação de um agente verbal é, em parte, nova ou particular, e essa singularidade leva-o a organizar, de certa forma, os tipos de discursos que constituem seu texto e a utilizar, de modo quase original, os recursos linguísticos próprios dos tipos.

Texto, então, é compreendido como um espaço social, histórico, cultural, linguístico e, ao mesmo tempo, singular, que revela hipóteses, escolhas que um "eu", escritor iniciante, levanta a respeito do seu objeto de estudo - a escrita ao se apropriar dos recursos linguísticos que sua língua materna dispõe para produzir, num dado espaço, num dado tempo, uma ação de linguagem direcionada a um "tu", no caso o professor, a fim de atingir um propósito comunicacional.

A partir dessa perspectiva, consideramos que os textos produzidos por aprendizes no processo de aquisição da escrita apresentam dados singulares. Em outras palavras, apresentam escolhas únicas que indicam que os sujeitos da linguagem realizam determinadas operações linguísticas buscando, a partir delas, construir a subjetividade bem como a alteridade, ou seja, compor na (sua) escrita: (i) o sujeito que enuncia; (ii) o interlocutor; (iii) a finalidade da interação; (iv) a temática; (v) o lugar e o tempo da produção, com a intenção de obter uma resposta, a priori, do professor, para ação de linguagem produzida (mesmo que essa ação seja direcionada ao professor).

Para representar na (sua) escrita essa situação de interlocução particular - a produção de texto na e para a escola - o aprendiz apresenta em sua produção textual marcas linguísticas que indicam uma representação termo a termo da oralidade, marcas que explicitam a conjunção do oral/falado e do letrado/escrito, marcas linguísticas que representam a escrita como estatuto de código institucionalizado (CORRÊA, 2004). No entanto, num dado momento do processo de aprendizagem, reconhece que: (i) a escrita, em alguns aspectos, 
não representa termo a termo a oralidade (OLIVEIRA, 2005), (ii) pode (e deve) ultrapassar os modelos de textos, discursos estabilizados pelas instituições como o texto "acartilhado6"- e, assim, estabelecer um processo de interlocução por meio do texto escrito, por meio da (sua) escrita.

Essa hipótese é ratificada por Soares (2005), ao dizer que o aprendiz da escrita, além de construir seu conhecimento e domínio do sistema ortográfico, deve construir também conhecimento e o uso da escrita como discurso, como uma atividade real de enunciação, necessária e adequada a determinadas situações de interação social, e concretizada em uma unidade estruturada - o texto - que obedece a regras discursivas próprias, sendo elas: recursos de coesão, de coerência, de informatividade, dentre outras. Este uso da língua como uma atividade real de enunciação, ou seja, o uso da língua como discurso é o que se vem denominando letramento ${ }^{7}$.

Pelos pressupostos teóricos expostos até aqui, fica claro que será assumida, neste artigo, a concepção de heterogeneidade da escrita, em conformidade com Corrêa (2004), para apreensão dos fatos linguísticos presentes no corpus de estudo. O autor diz que a escrita é permeada pela fala, ou seja, que a escrita é heterogênea, aspecto que caracteriza a concepção de modo heterogêneo de constituição da escrita, a base dos estudos do linguista. Afirma ainda que fala e escrita são dois sistemas semióticos distintos, mas que se inter-relacionam em função de uma indissociabilidade entre os fatos linguísticos e sociais relacionados à oralidade/fala e ao letramento/escrita.

Para análise do fenômeno do encontro entre oralidade e escrita, consideradas pelo autor como práticas sociais, foram criados três eixos de representação da escrita pelos quais os estudantes em situação de vestibular sujeitos da pesquisa do estudioso - circulam em sua prática textual. Os eixos em questão são os seguintes: o da representação que o escrevente faz sobre o

${ }^{6} \mathrm{O}$ termo texto "acartilhado" refere-se as cartilhas, práticas de uma escrita artificial, realizada em "exercícios" de criar listas de palavras soltas ou, ainda, de formar frases justapostas.

7 O termo Letramento utilizado neste artigo refere-se a aprendizagem inicial da língua escrita compreendida não apenas como aquisição do sistema alfabético e suas convenções, mas como a introdução da criança às práticas sociais da língua escrita, à cultura do escrito. 
que imagina ser a gênese da (sua) escrita; o da representação que o escrevente faz sobre o que imagina ser o código escrito institucionalizado e o da representação que o escrevente faz sobre a dialogia com o falado/escrito e com o já ouvido/lido.

De modo simplificado, pode-se dizer que a concepção de heterogeneidade da escrita defendida pelo autor está centrada nos seguintes aspectos, a saber: (i) a fala e a escrita são compreendidas como modos de enunciação ligados às práticas de oralidade e de letramento; (ii) as marcas de fatos ligados à enunciação oral presentes em enunciados escritos constituem indícios do modo heterogêneo de constituição da escrita; (iii) a escrita é vista em seu processo de produção; (iv) a relação oral/falado e letrado/escrito é vista sempre a partir da relação sujeito/linguagem; e (v) a circulação dialógica do escrevente e/ou a imagem que o escrevente faz da escrita são sempre consideradas como parte de um imaginário socialmente partilhado.

Compreender a escrita como heterogênea é entender que tal tecnologia apresenta um caráter inacabado, ou seja, ela possui uma natureza processual e, portanto, não pode ser vista como um produto pronto, caracterizado pela pureza. Assim, o aprendiz, aquele que está no controle da construção do conhecimento, ao realizar o processo de produção da (sua) escrita, ou seja, ao realizar uma atividade de produção de linguagem por meio do texto escrito, irá registrar: (i) marcas linguísticas que indicam uma representação termo a termo da oralidade; (ii) marcas que explicitam a conjunção do oral/falado e do letrado/escrito; e (iii) marcas linguísticas que representam a escrita como estatuto de código institucionalizado. (CORRÊA, 2004)

Essa tese permite adotar a concepção de aprendizado da escrita proposta por Oliveira (2005), ao afirmar que a escrita é um processo de construção de conhecimento intermediado pela oralidade, ou seja, por aquilo que o aprendiz já conhece sobre a língua falada. Nas palavras do linguista, "o conhecimento sobre a língua falada controla o processo de aprendizado da língua escrita." (OLIVEIRA, 2005, p. 16). No entanto, o autor ressalta que nem 
tudo que constitui o nosso conhecimento da escrita tem origem no nosso conhecimento da língua falada, "que, diga-se de passagem, é diferente de grupo para grupo, sejam esses grupos diferenciados em termos sociais, etários ou geográficos." (OLIVEIRA, 2005, p. 16).

De acordo com Oliveira (2005), há aspectos sociais (a fala de qual grupo serve de modelo para aquilo que se escreve?), históricos (parte da nossa escrita é de natureza etimológica, refletindo diferenças de fala que hoje não existem mais), convencionais (boa parte das relações que se estabelecem entre sons e letras são reguladas por convenções) e textuais (gêneros textuais diferentes selecionam modos diferentes de se escrever), que fazem parte igualmente do domínio da escrita.

A concepção de aprendizagem da escrita proposta por Oliveira (2005) permite dizer que o aprendiz da escrita, é capaz de interagir com o seu objeto de aprendizagem por meio de hipóteses formuladas e reformuladas sobre o objeto. O falante da língua leva em consideração aquilo que conhece de primeira mão sobre a língua - conhecimento esse que é de natureza oral. Portanto, ele transfere, nas suas primeiras hipóteses sobre a escrita, algumas das características da fala.

O pesquisador ainda afirma que, enquanto seres humanos, somos geneticamente dotados de esquemas mentais que nos permitem aprender e realizar uma série de operações importantes, como por exemplo, generalizar, criar conceitos. Esse aprendizado não se dá no vazio, mas está inserido no contexto social que nos cerca. Ou seja, não aprendemos sozinhos, reinventando a língua, mas aprendemos sob o controle do grupo social em que nos inserimos.

Em suma, o conjunto de princípios teóricos acima apresentados contribui para que os chamados "erros" sejam analisados, interpretados e descritos como "hipóteses brilhantes" (HERMONT, 2010), que o sujeito da linguagem opera para construir o conhecimento e o uso da tecnologia da escrita como discurso, como enunciação. 


\section{Os corpora e a metodologia empregada}

Os textos utilizados nesta investigação foram coletados pelo professor Dr. Marco Antônio de Oliveira $^{8}$ e outros pesquisadores, no ano de 1987, durante uma pesquisa a respeito do processo de aquisição da escrita, realizada na Faculdade de Letras e na Faculdade de Educação da Universidade Federal de Minas Gerais - UFMG. São dados de natureza transversal - textos realizados por diferentes informantes, em momentos determinados do desenvolvimento escolar de tais indivíduos - e coletados de forma naturalística e com base em variáveis sociolinguísticas (origem, sexo, faixa etária, grau de escolaridade, classe social).

Os critérios de organização dos 320 textos coletados, incluindo os que escolhemos para serem analisados neste artigo, foram os seguintes: (i) instituição escolar de origem (pública ou privada); (ii) grau de escolaridade (primeira à oitava série); (iii) faixa etária (criança ou adulto); (iv) classe social (privilegiada ou popular); (v) sexo (masculino e feminino). Além de tais critérios, os textos que compõem os corpora de estudo são do tipo textual narrativo (Era uma vez, Um sonho.) e majoritariamente do tipo argumentativo (Se eu pudesse, Meu brinquedo preferido).

Por questões de tempo e espaço não será possível analisar, no escopo desta proposta, os 320 corpora coletados e cedidos para pesquisa. Portanto, serão analisados dois textos: (i) o primeiro pertencente ao tipo argumentativo, produzido por uma criança, falante de instituição privada, da 1a série, do sexo masculino, pertencente à classe social privilegiada; (ii) o segundo pertence também ao tipo argumentativo, mas produzido por uma criança, falante de instituição pública, da $1^{\underline{a}}$ série, do gênero masculino, pertencente à classe popular.

\section{O procedimento metodológico}

${ }^{8}$ Atualmente é prof. adjunto da Pontifícia Universidade Católica de Minas Gerais - (PUC-MG). Entretextos, Londrina, v. 15, n. 2, p. 193-215, jul./dez. 2015. 
De Abaurre (2003), será adotada a metodologia denominada paradigma indiciário de investigação, definido pela autora como

[...] um modelo epistemológico, fundado no detalhe, no "resíduo", no episódico", no singular, a partir do pressuposto de que, se identificados a partir de princípios metodológicos previamente definidos, os dados singulares podem ser altamente reveladores daquilo que se busca conhecer. A opção feita por focalizar os dados singulares permitiu a observação de que certos sujeitos parecem definir preferências em seu trabalho com a linguagem. (ABAURRE; MAYRINK-SABISON, 2003, p. 168).

A autora ainda afirma que o paradigma indiciário de investigação, proposto por Ginzburg (1990), tem se revelado produtivo para a discussão das questões associadas ao discurso, à subjetividade e à alteridade, como é o caso desta investigação, que pretende analisar que operações linguísticas são realizadas pelo falante para representar na (sua) escrita, o sujeito que enuncia, o interlocutor, a temática, a finalidade da interação, o tempo e o espaço da enunciação.

\section{A análise e descrição: o que dizem os dados?}

Para iniciar a descrição e análise dos dados, o leitor deste artigo está convidado a observar os dois textos seguintes:

Quadro 2 - Texto 2: falante da classe privilegiada

Se eu podesseter um esqueite

Se eu podesseter um rádio

Se eu pudesse ser adivogado

Se eu pudesse ter uma bisicleta

Fonte: Dados da pesquisa.

Quadro 3 - Texto 3: falante da classe popular 


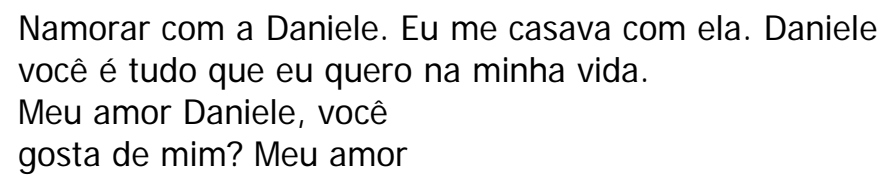

Fonte: Dados da pesquisa.

Neles, dois falantes do gênero masculino, estudantes da $1^{\text {a }}$ série, pertencentes, um (texto 2) à classe privilegiada, outro (texto 3) à classe popular, se enunciam como "eu" e, ao mesmo tempo, instauram um "tu", um outro, para o exercício da faculdade da linguagem, para a realização do ato de enunciação. Há, portanto, como afirma Benveniste (1995, p. 250), “uma pessoa implicada e um discurso sobre essa pessoa". No entanto, existem algumas diferenças entre os dois textos, mesmo sendo respostas para um mesmo tema: "Se eu pudesse".

No texto 2, o "eu" que enuncia realiza uma ação de linguagem a partir de um lugar físico: o da escola. Portanto, o seu estatuto de enunciador é o de aluno e, por tal, instaura o professor como o "tu", como seu interlocutor para o exercício da faculdade da linguagem, esta materializada e processada por meio de um texto empírico. Dessa forma, ao se enunciar como "eu-aluno", tendo como parâmetro para realização da (sua) escrita o "tu-professor", o sujeito que enuncia busca realizar o tema "Se eu pudesse..." com e por um único objetivo: fazer o discurso que o seu interlocutor escolar quer ler, portanto, produzir um texto no formato de uma cartilha e, assim, provocar um efeito de sentido, ou seja, demonstrar ao professor que é capaz de reproduzir o discurso da escola.

Nesses termos, o falante constrói a (sua) escrita como estatuto de código institucionalizado, pois repete um modelo de organização textual "acartilhado," reconhecido e legitimado pela instituição de educação que frequenta. $\mathrm{O}$ escrevente pertencente à classe privilegiada sabe, então, quais são as expectativas do seu interlocutor escolar e organiza sua produção textual para obter acerto, pois tem certo conhecimento, como propõe Bronckart (1999), dos gêneros e tipos em uso, considerados como modelos e exemplos. 
Sabe, portanto, que o gênero/tipo aceito na escola, o modelo ou exemplo de texto na esfera escolar é a cartilha.

Para se enunciar como "eu-aluno" e mostrar ao "tu-professor" que sabe escrever segundo o "modelo" proposto pela escola, o falante do texto 2, ao discorrer a respeito do tema "Se eu pudesse..." cria uma lista de orações justapostas - "ter um esqueite", "ter um rádio", "ser um adivogado", "ter uma bicicleta" - sem elementos de coesão para estabelecer a continuidade do discurso, sem nenhuma marcação de ponto final, por exemplo. Repete, no início de todas as sentenças, o tema da redação "Se eu pudesse", aspecto que sinaliza que as orações são respostas organizadas pelo falante no formato de cartilha para cumprir uma tarefa escolar.

Nesse sentido, o "tu-professor" está fortemente marcado no texto do "eu-aluno", que fala de si, do que gostaria de ter e de ser, expressa sua subjetividade, mas por meio de uma organização textual com repetição, sem variação de superestrutura, de organização, de sequência de suas partes. Essa organização textual "acartilhada", composta de frases justapostas, sem elementos de coesão e de coerência, sem variação de superestrutura, de organização, de sequência de partes é um dado singular, uma preferência do falante, produtor do texto 2 , que indica, na macroestrutura, uma tentativa de alçamento do escrevente ao que imagina ser a escrita enquanto estatuto de código institucionalizado (CORRÊA,2004).

Ao mesmo tempo, podemos afirmar que fazer uso da estrutura de uma cartilha para construir na (sua) escrita: (i) o sujeito que enuncia; (ii) o interlocutor; (iii) a finalidade da interação; (iv) a temática; (v) o lugar e o tempo da produção, advém de um imaginário socialmente partilhado, como propõe Corrêa (2004). Escrever na escola e para a escola, principalmente no processo de alfabetização é, na maioria dos casos, a formulação de uma lista de sentenças independentes, sem uso de continuadores discursivos, sem sinais de pontuação, como posto por Soares (2005). Assim, o falante da classe privilegiada utiliza a escrita como a escola imagina que ela seja. 
No que diz respeito à construção do sistema ortográfico, observamos que ocorrem marcas linguísticas, em outros termos, fatos ligados à enunciação oral presentes em enunciados escritos, como: podesseter, adivogado. Tais marcas, como exposto nas considerações iniciais desta investigação, representam para alguns professores alfabetizadores "erros" de escrita. No entanto, consideramos que tais "erros" são indícios do modo heterogêneo de constituição da escrita (CORRÊA, 2004). Representam a construção de hipóteses, a relação do sujeito/linguagem, a circulação do escrevente por práticas sociais do oral/falado e o do letrado/escrito.

Em "podesseter", o falante realiza duas operações linguísticas ao escrever, sendo elas: a operação denominada de hipercorreção (OLIVEIRA, 2005; HERMONT, 2010) e a operação intitulada junção de palavras (OLIVEIRA, 2005; HERMONT, 2010). Além de marcarem a circulação do escrevente por práticas sociais do oral/falado e do letrado/escrito, elas indicam as hipóteses que o sujeito formula e reformula sobre o objeto escrita. A operação de hipercorreção ocorre quando o falante escreve "podesse" no lugar de "pudesse", ou seja, transforma uma vogal alta [u] em uma vogal média-alta [o] a fim de ajustar-se ao que ele acredita ser a norma padrão.

É uma tentativa de corresponder às expectativas do seu interlocutor: o professor. O escrevente fica tão preocupado em não errar que acaba corrigindo o que não é para corrigir. Ele sabe que a palavra "pudesse" deve ser grafada com $u$ e não com $o$, pois em outros momentos de sua produção percebe-se a grafia ajustada à norma padrão "pudesse".

O aluno está tão preocupado com sua imagem, com a imagem que irá apresentar na (sua) escrita para seu interlocutor, o professor, que acaba cometendo o desvio "podesse" porque, como afirma Hermont (2010), a professora deve ter corrigido a grafia de "u", colocando "o", em algumas palavras. Então, em "pudesse," a vogal "u" deve ser também substituída por "o", de acordo com a hipótese do falante. Ocorre então, a circulação do 
escrevente ora por práticas sociais do oral/falado "podesse", ora por práticas sociais do letrado/ escrito "pudesse".

Nessa perspectiva, a "hipercorreção" é, então, uma materialidade linguístico-discursiva, uma operação que acontece porque o falante, produtor do texto 2 , deseja a normatividade e, ao mesmo tempo, possui um imaginário de "correção" de língua construído. O escrevente, ao falar de si, do que ele, hipoteticamente, poderia ter ou ser, quer corresponder às expectativas do seu professor tanto no que diz respeito ao sistema ortográfico como também no que tange à organização textual apresentada no formato de uma cartilha.

Já a junção de palavra ${ }^{9}$ outra operação linguístico-discursiva realizada pelo falante, pertencente à classe privilegiada. Tal operação ocorre porque o aprendiz escreve em termos de unidades de acento "podesseter", o que ocorre na fala, e não em termos de unidades de sentido, por palavras morfológicas, como "pudesse ter". O falante escreve, juntas, as duas palavras morfológicas (verbos) pudesse e ter, pois elas são pronunciadas juntas, constituindo apenas uma palavra fonológica "pudesseter". Ocorre a violação de sequências de palavras não porque "o falante não sabe escrever", mas porque o processo de aquisição da escrita está intermediado pela oralidade, como propõe Oliveira (2005).

Além disso, o dado singular "podesseter," se comparado a outros "pudesse ter" e "pudesse ser," indicam que o "eu-aluno", ao falar de si, de sua subjetividade, ao se constituir como sujeito e constituir o "tu-professor" como seu interlocutor, realiza tanto uma representação termo a termo da oralidade como uma representação calcada no letrado/escrito. Oscila entre "Se eu podesseter um esqueite" $e$ "Se eu pudesse ser advogado" / "Se eu pudesse ter uma bisicleta".

Por último, outro dado que evidencia o registro de marcas do oral/falado é a operação linguístico-discursiva intitulada como epêntese, processo que

9 Termo utilizado por Oliveira (2005) e Hermont (2010). Outros autores (ABAURRE, 1991; SILVA, 1994; CHACON, 2006) utilizam o termo hipossegmentação.

Entretextos, Londrina, v. 15, n. 2, p. 193-215, jul./dez. 2015. 
ocorre em "adivogado". A inserção de uma vogal epentética "i", após a consoante oclusiva "d", sugere que o falante da língua tem a finalidade de simplificar o encontro consonantal formado em advogado por "adivogado". Dessa forma, em seu trabalho com a linguagem, o escrevente apresenta uma nítida preferência pelo padrão canônico Consoante-Vogal (CV), aspecto que revela um dado singular, como propõe Abaurre e Mayrink-Sabison (2003).

O autor do texto 3, falante da classe popular, ao contrário do falante do texto 2, não utiliza o tema "Se eu pudesse" para cumprir um objetivo escolar, no formato de um texto "acartilhado". Apesar do falante da classe popular produzir o texto no lugar físico intitulado escola, quando convidado a escrever sobre o tema "Se eu pudesse", ou seja, quando convidado a falar de si, de sua subjetividade, de seus desejos, o papel social que ele desempenha na interação escrita em curso não é o de aluno. Portanto, não tem como parâmetro para produzir a (sua) escrita apenas o professor. Assim, a finalidade da interação marcada na enunciação realizada não é meramente escolar, a de cumprir uma tarefa.

O "eu" que enuncia se apropria dos recursos abstratos, formais de sua língua, designando-se, no interior da enunciação escrita, como "Eu”, “me”, "eu quero", "minha", "meu" e "mim". Os pronomes pessoais "Eu", "me" e "mim" bem como os possessivos "minha" e "meu", além de atuarem como ponto de apoio para a "... revelação da subjetividade na linguagem." (BENVENISTE, 1995, p. 288), exercem a função de recursos coesivos que, no interior da enunciação escrita, retomam e, ao mesmo tempo, marcam o "Eu" que enuncia (1a linha), aspecto que confere progressão e referenciação ao discurso. Desse modo, ocorrem duas operações textuais-discursivas que podem ser intituladas como operação anafórica e operação de referenciação.

Ao realizar essas operações textuais, além de revelar a instância enunciativa "eu", explicita também um "tu", representado, referenciando, a partir do emprego de vários recursos formais - Daniele (substantivo), "ela" (pronome pessoal feminino), você (pronome pessoal), "tudo" (pronome 
indefinido), "meu amor" - com o objetivo de expressar sua subjetividade, seus sentimentos, desejos e, ao mesmo tempo, indagar seu interlocutor "Daniele, você gosta de mim?", num dado tempo e espaço enunciativo, na expectativa de obter uma resposta, gerar uma outra ação de linguagem.

O "eu" que enuncia assume o tempo bem como o espaço enunciativo posto pela temática "Se eu pudesse", pois, ao iniciar seu texto, faz uso do verbo no infinitivo "Namorar com a Daniele", exigido pelo verbo "pudesse", que indica o pretérito-imperfeito do subjuntivo. O mesmo ocorre com "Eu casava", no pretérito perfeito do indicativo. Além disso, quando o falante afirma "Daniele você é tudo que eu quero na minha vida", "Daniele, você gosta de mim?" anuncia a construção do espaço e do tempo da enunciação, que estão na dependência do eu, que neles se anuncia. Quando diz "quero", essa forma verbal flexionada situa o interlocutor, o "tu-Daniele", no âmbito espaçotemporal do "eu", marca o que ele anuncia para o "tu" no aqui - o texto como espaço enunciativo - e no agora - o presente da enunciação. Desse modo, percebe-se a tríade eu-tu $\leftrightarrow$ aqui $\leftrightarrow$ agora.

Por último, verificamos que, para compor essa tríade, a temática "Se eu pudesse" e a finalidade da enunciação escrita, a marca morfossintática "tudo que" - evidencia que o escrevente, de modo intuitivo, faz uso de uma das duas formas [tudo o que/com antecedente] ou [tudo que/sem antecedente], aceita pelo padrão mais formal da língua. No entanto, segundo a prescrição gramatical, o mais usual na escrita é o emprego do relativo "que" com o pronome demonstrativo "o".

Dessarte, entre as duas opções apresentadas, o falante emprega o pronome sem o antecedente expresso - forma mais usual na fala - apesar de ser aceita pela prescrição gramatical. Logo, o uso de [tudo que] reflete na escrita do falante da classe popular tanto a conjunção entre o oral/falado e o letrado/escrito como também a tentativa de alçamento ao padrão mais formal da língua, ou seja, o escrevente representa o modo heterogêneo de constituição da escrita (CORRÊA, 2004). 
Outro aspecto que evidencia a tentativa de alçamento ao padrão mais formal da língua é a ausência de "erros" do ponto de vista da construção do sistema ortográfico. Ao contrário do autor do texto 2, o falante da classe popular não transfere, nas suas primeiras hipóteses sobre a escrita, algumas das características da fala, como a operação de junção de palavras, por exemplo.

Assim sendo, ocorre o que afirma Oliveira (2005, p. 16): "[...] e o que se espera, a longo prazo, é que sejamos capazes de tratar a língua falada e a língua escrita de modo independente, e que a escrita se torne autônoma em relação à fala." Em resumo, há um momento em que nenhum de nós escreve mais como fala. Ao que tudo indica, o autor do texto 3 já construiu essa hipótese no que tange à construção do sistema ortográfico.

\section{Considerações finais}

Ao longo desta interlocução escrita procuramos responder a seguinte indagação: Que operações linguísticas são realizadas pelo falante para representar na (sua) escrita cenas enunciativas? Para tanto, foram analisados 2 textos produzidos por dois falantes pertencentes às classes privilegiada e popular, ambos aprendizes da 1a série (na época da coleta dos dados), em busca de dados singulares, como propõe a vertente metodológica denominada paradigma indiciário.

Foi possível observar - a partir da análise dos dados linguísticos e com base no quadro teórico assumido - que os falantes, quando convidados a produzirem textos a partir do tema "Se eu pudesse", precedem de modo distinto, uma vez que a imagem que esses sujeitos da linguagem fazem da escrita é sempre considerada como parte de um imaginário socialmente partilhado (CORRÊA, 2004).

Em outras palavras, a aprendizagem da escrita ocorre sob o controle do grupo social a que pertencem os falantes (OLIVEIRA, 2005). Destarte, as 
operações linguísticas realizadas para representar a situação de enunciação escrita - o sujeito que enuncia, o interlocutor, a temática, a finalidade da interação, o tempo e o espaço da enunciação - são diferentes.

No que diz respeito ao texto produzido pelo falante pertencente à classe privilegiada, os dados revelaram que os aspectos ligados à microestrutura textual, como a hipercorreção, a junção de palavras e a epêntese, presentes no texto 2, estão à serviço da macroestrutura, do discursivo, da enunciação, já que podem ser considerados como dados singulares, escolhas únicas que evidenciam operações linguísticas realizadas pelo falante para representar na (sua) escrita o sujeito que enuncia, a imagem que tal sujeito faz da (sua) escrita bem como a sua circulação pelas práticas do oral/falado e do letrado/escrito. Não são, por conseguinte, "erros" ou "inadequações", mas evidências da relação sujeito/linguagem.

A operação de hipercorreção, por exemplo, deixa claro o desejo que o "eu-aluno" tem de pertencer ao grupo dos que "sabem" falar e escrever como também mostrar ao seu interlocutor, o "tu-professor", que sabe produzir a escrita que a escola quer. Deseja a normatividade e, ao mesmo tempo, possui um imaginário de "correção" de língua construído.

Tal operação demonstra então que o falante pertencente à classe privilegiada quer corresponder às expectativas do seu interlocutor no que diz respeito ao sistema ortográfico, ou seja, quer escrever "corretamente", a partir de uma organização textual "acartilhada". Ao mesmo tempo, ao considerar a temática para falar de si, do que, hipoteticamente, poderia ter ou ser, ao instaurar o professor como seu interlocutor, quer fazer da (sua) escrita um espaço de enunciação. Por tal, demonstra um grande conflito.

O falante pertencente à classe popular, ao contrário do falante da classe privilegiada, percebe que pode (e deve) ultrapassar os modelos de textos "acartilhados", estabilizados por algumas instituições de educação e, assim, estabelecer um processo de interlocução que vai além dos muros e dos objetivos da escola quando, por meio do texto escrito, por meio da (sua) 
escrita, não institui o professor como seu único interlocutor. Instaura o professor como o seu interlocutor ao escrever "Namorar com a Daniele. Eu me casava com ela", resposta apresentada para a temática "Se eu pudesse". Mas, em outro momento, a enunciação escrita já é direcionada ao "tu-Daniele", no aqui e no agora, com a finalidade de expressar seus sentimentos, falar de si, de sua subjetividade "Daniele você é tudo que eu quero na minha vida. Meu amor Daniele, você gosta de mim?".

Logo, faz uso da escrita como discurso, como uma atividade real de enunciação, necessária e adequada a determinadas situações de interação social e concretizada em uma unidade estruturada - o texto - que obedece a regras discursivas próprias, sendo elas: recursos de coesão, de coerência, de referenciação, de informatividade, ao realizar a operação anafórica e operação de referenciação.

Em suma, esperamos que os resultados parciais desta investigação possam contribuir para o entendimento do processo de aquisição da escrita ao mostrar que os fatos linguísticos entendidos como "erro" no texto 2 e 3, por exemplo, revelam a relação do falante com as práticas sociais do oral/falado e o do letrado/escrito bem como indicam a presença de operações linguísticas necessárias para a construção da subjetividade e da alteridade na escrita, ou seja, a relação sujeito/linguagem.

Apesar dos dados utilizados representarem uma pequena amostra, já é possível observar que a escrita do aprendiz em fase de aquisição da escrita traz marcas de subjetividade e de singularidade. O falante, portanto, aparece em sua alteridade ao representar (na) sua escrita o sujeito que enuncia, o interlocutor, a temática, a finalidade da interação, o tempo e o espaço da enunciação.

\section{Referências}

ANTUNES, Irandé. Aula de português. encontro e interação. São Paulo:

Parábola Editorial, 2003. 
ABAURRE, Maria Bernadete Marques. A relevância dos critérios prosódicos semânticos na elaboração de hipóteses sobre segmentação na escrita inicial. Boletim da Abralin, Curitiba, v. 11, p. 203-217, 1991.

ABAURRE, Maria Bernadete Marques; MAYRI NK-SABISON, Maria Laura Trindade. Considerações sobre a diferenciação de gêneros discursivos na escrita infantil. In: ROCHA, Gladys; VAL, Maria da Graça Costa (Org.). Reflexões sobre as práticas escolares de produção de texto. Belo Horizonte: CEALE; Autêntica, 2003. p. 167-184.

BENVENISTE, Émile. Problemas de linguística geral. 4. ed. Tradução de Maria da Glória Novak e Maria Luisa Neri. Campinas: Pontes, 1995.

BRONCKART, J ean-Paul. Os textos e seu estatuto: considerações teóricas, metodológicas e didáticas. In: discurso. São Paulo: EDUC, $19 \overline{99}$. . Atividade de linguagem, textos e

CHACON, Lourenço. Algumas palavras sobre a relação entre oralidade e letramento em hipersegmentações na aquisição da escrita. In: CORRÊA, Manoel Luiz Gonçalves (Org.). Práticas escritas na escola: letramento e representação. São Paulo: Convênio CAPES/COFECUB - Projeto 510/05, 2006. p. 57-61.

CORRÊA, Manuel Luiz Gonçalves. O modo heterogêneo de constituição da escrita. São Paulo: Martins Fontes, 2004.

GINZBURG, Carlo. Sinais: raízes de um paradigma indiciário. In: . Mitos, emblemas, sinais. morfologia e história. São Paulo: Companhia das Letras, 1990. p. 143-179.

HERMONT, Arabie Berzi. Como analisar textos de alunos em processos de aquisição da escrita. Pedagogia em Ação, Belo Horizonte, v. 2, n. 1, p. 27-39, 2010. Disponível em: <http://periodicos. pucminas.br/index.php/pedagogiacao/ article/view/4478>. Acesso em: 29 jun. 2015.

MARCUSCHI, Luiz Antonio. Da fala para a escrita: atividades de retextualização. 2 ed. São Paulo: Cortez, 2001.

OLIVEI RA, Marco Antônio. Conhecimento linguístico e apropriação do sistema de escrita: caderno do formador. Belo Horizonte: Ceale/FaE/UFMG, 2005. (Coleção Alfabetização e Letramento).

SILVA, Ademar. Alfabetização: a escrita espontânea. São Paulo: Contexto, 1994.

SOARES, Magda. Alfabetização e Letramento. 3. ed. São Paulo: Contexto, 2005. 